\title{
Feedback generation and linguistic knowledge in 'SLIM' automatic tutor
}

\author{
RODOLFO DELMONTE \\ Department of Language Sciences, Ca' Garzoni-Moro - San Marco 3417, \\ Università Ca'Foscari - 30124 VENEZIA (Italy) \\ (email:delmont@unive.it)
}

\begin{abstract}
SLIM is a prototype interactive multimedia self-learning linguistic software for foreign language students at beginner-false beginner level. It allows students to work both in an autonomous self-directed mode or in a way of programmed learning in which the process of self-instruction is pre-programmed and monitored. In this latter mode it incorporates assessment and evaluation tools in order to behave as an automatic tutor. It is organized into three basic components: audiovisual materials; a linguistic database recording all language material in text format; the supervisor. Audiovisual materials are partially taken from commercially available courses; the linguistic database is a highly sophisticated classification of all words and utterances of the course, both in written and spoken form, from all possible linguistic aspects. The supervisor is both an attractive, enjoyable and strongly pedagogically based software that allows the user to work on language materials. The most outstanding feature of SLIM is the use of speech analysis and recognition which is a fundamental aspect of all second language learning programmes. We also assume that a learning model can be represented by a finite state automaton made up by a fixed number of possible states - corresponding to the macro and microlevels at which the student's competence may be modelled - each one being internally constituted by the actual linguistic objects of knowledge of the language that make it up.
\end{abstract}

\section{Introduction}

SLIM - Interactive Multimedia self-learning Linguistic Software, is a multimedia course for self-instruction which allows students to work both in an autonomous and independent self-directed mode or in a way of programmed learning in which the whole process of self-instruction is preprogrammed and monitored. At present, the prototype we are working on is directed to real beginners of both western languages like Italian, English and French, and eastern languages like Chinese and Japanese.

Self-instructional materials should have all the features good language teaching materials have - interest, variety, clarity and so on. However the following points seem paramount:

- a clear statement of objectives;

- meaningful language input; 
3-Delmonte-209-234-x 4/11/02 5:09 pm Page 2

- a sufficient number of exercise materials and of activities - their feasibility for self-instructional use;

- $\quad$ individualisation and flexibility of materials;

- learning instructions in mother tongue for the levels considered here, with information in each unit giving advice on the order in which various activities should be done, how they are to be done; how much time they should take, whether they should be done over a short time interval or paced over a number of days;

- language learning advice - it is essential for the learner to be told about how to tackle the job of language learning. Help facilities should explain how to do exercises and activities; how to learn vocabulary; whether or not to set out to learn lists of irregular verbs and explicit grammatical rules; how and when to use reference materials such as dictionaries and grammar hypertext; how to plan the work and how to pace it; how intensively to study and how to motivate oneself; how to assess attainment and how to keep records of progress;

- feedback and tests - the provision of feedback to the learners in the form of answers and explanations to exercises provides a major opportunity for learning in self-instructional materials. It is important to remember that learners need to know why they are wrong and where they are wrong.

\section{Courseware architecture}

SLIM courses may be accessed in two modes, according to students' attitudes:

1. Exploratory or Free Mode, self-access for self-directed students with no supervision by the Human Tutor or the Automatic Tutor (HT or AT);

2. Directed or Guided Mode, self-access for beginners who use self-contained materials which are internally programmed and supervised by the HT or AT.

In the first mode, the courseware is available with free access to all the components, so that one can simply decide to organize an individualized path through them by activating the appropriate mode and following through the different activities available.

In either case, there is continuous support to the learners when they decide to engage themselves in one or the other mode, in order to advise them as to the setting up of goals which are adequate to their previous knowledge, expectations, and needs. The course is introduced by a general presentation where all different modules and activities are illustrated and exemplified. In addition, each module has been supplied with a Help facility, a sort of Coach, which illustrates pedagogical issues relevant to the current exercise.

In the Directed Mode, the software is organized into Activities and Modules. Responsibility for the learning processes and corresponding tasks as well as for the decision-making processes for learning is expressly built into the materials: by this we mean that the student will not be allowed to go from level 1 to level 2 unless s/he has completed all drills with the required skill. In order to do this the course is programmed in such a way as to allow for graduality in the presentation of materials and to include effective tools for self-assessment. Learners who assess themselves should be aware of how well they achieve learning tasks, and have a reasonable idea of their level of proficiency.

In the Exploratory Mode, activity units are freely accessible from a database structure 
in which students may access them, starting from goals. Students/tutors can design their own courses, and the ways that the achievement of their selected goals may be assessed, as well as when to take their tests. In other words, students may select preferred learning modes and strategies. It is clear that in this second mode, materials are proposed without any internal structure and students should be aware of their needs.

\subsection{SLIM functional components}

The following are SLIM functional components:
a. The Supervisor
b. Media
c. Linguistic Database
d. Hypertexts
e. Help
f. Testing
g. Translations
h. Dictionary

We shall describe The Supervisor component last. Media refer to all media used by The Supervisor: they include the following:

- Animation: video English + project video $1=73$ video-clips

- Controlled utterances: 2700 utterances, including: Grapevine and Two Days in Summer

- $\quad$ Spoken Dictionary: 2000 words

The second component, the Linguistic Database is currently being organized under FileMaker ${ }^{\mathrm{TM}}$, and includes the following items and descriptions:

- 1800 word types;

- 11,000 word tokens;

- 2700 utterances;

- 122 communicative functions;

- 27 syntactic/semantic classes;

- 500 grammatical classes (POS tagging, i.e. part of speech labels);

- Phonetic transcription

- Soundex coding for each word

The third component, Hypertexts, includes the following items:

- Grammar

- Phonetics

- Culture \& Civilization

The fourth component Help, has both animated and textual help instructions for each 
3-Delmonte-209-234-x 4/11/02 5:09 pm Page 4

activity. The fifth component is the manual annotated translation attached to each word and utterance of the course; and finally the sixth component is a monolingual dictionary required for Advanced Activities.

Now, coming back to the first component, The Supervisor, this is divided up into the following Modules and Activities:

- 6 teaching modules

- 4-5 activities per module

1. Oral module - audiovisual teaching units; (watching and listening).

2. Written module - writing skills; (graphematics, phonotactics).

3. Grammar module - remedial linguistic activities; (grammar-syntax-semantics), self-assessment and testing.

4. Phoneticmodule - audio-speaking practice; (phonetics).

5. Prosodic module - audio-speaking practice; (prosodics).

6. Advanced module - advanced exercises; (understanding and role-taking).

All these components are made available as a self-access system based on multimedia software that allows the student to work in audio-active-comparative mode but also using Automatic Speech Recognition (ASR). Each student executes her/his activities by means of a headset for speaking-listening tasks. ASR will provide feedback if the student activates it.

However, we know that before thinking about automatic or semi-automatic advisor/tutor, the overall architecture of the system should satisfy certain requirements: in particular, performance data on which to base automatic decisions should come from online assessment and evaluation tools: in addition, these tools should be completely and consistently related to the teaching/learning materials studied. They should also have other important features such as the ability to address oral skills and not only written ones, and be fully integrated with one another.

SLIM allows for a direct mapping between learning/teaching materials and assessment. Most activities are built by the system automatically tapping linguistic knowledge encoded in the database by means of procedures that look for certain linguistic items, in a given order, according to certain teaching criteria which have been implemented directly in each procedure. SLIM's basic activities are all related to spoken activities where communicative goals are highlighted and adequately motivated. Figure 1 shows Slim's architecture with links among its internal deep components.

\section{Automatic tutor}

In what follows, automatic tutoring will be described in terms of interaction between Student Model and Language Tutor which in turn is made up of a Pedagogical Component and a Linguistic Knowledge Database.

\subsection{The student profile and student-tutor interaction}

In Figure 2 we show the chart concerning the high level of SLIM supervisor with 


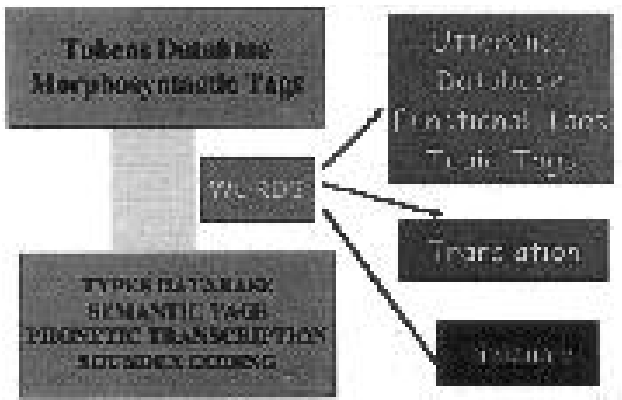

Fig. 1. SLIM relational databases architecture.

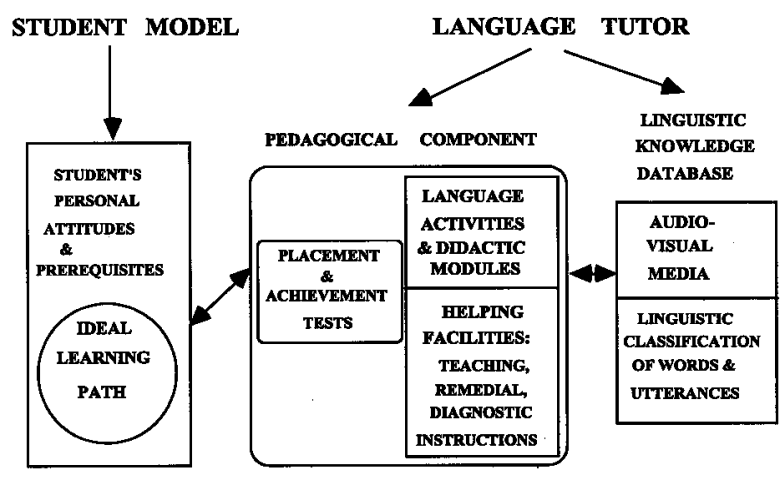

Fig. 2. SLIM Automatic Tutor architecture.

internal macro-definitions and arrows to indicate their interaction. As will be made clear in this section and in following ones, the Automatic Tutor function is strongly interconnected to the Student Profile component. The following is a list of essential factors determining Student's Profile when learning a second language:

1. Language distance

2. Interlanguage continuum

3. Study style

4. Learning approach

5. Time available to execute the task

6. Student's background

7. Confidence in mastering learning solutions

We addressed all such factors by the following questions organized in a questionnaire:

1. What languages can you speak apart from 'Source Language'?

2. How many years have you been studying 'Target Language'?

3. Which way should the contents of the course be presented:
a. Bottom-up
b. Top-Down 

c. Analytic
d. Synthetic
e. Serialist
f. Holistic

4. Which way do you prefer to study:
a. Directive
b. Exploratory

5. How much time can you spare to reach your learning objectives?

6. Was your secondary school an educational or a vocational one?

7. Have you already been working on a computer interactively?

There are three possible outcomes of the questionnaire:
A. Call the human tutor - (Fully directed)
B. Call the automatic tutor - (Automatic Tutor)
C. Choose the best learning path-(Half-directed)

where in A. the Human Tutor is only the Virtual Tutor, and could be reached on a local or geographic network connection; in $\mathrm{C}$. the best learning path could either be chosen by the student or by the Human Tutor if locally available and is the only physically present tutor. In B. a call to the Automatic Tutor only realizes a virtual call with no human physically present tutor, and in this case the first requirement would be to go through a placement test which should make available enough data to the system to organize a first fully automatic learning path.

What kind of knowledge should the Automatic Tutor possess after Student Profile and Placement Test have been completed? We assume that the following is in order:

1. Conceptual knowledge - coinciding with grammar of L2.

2. Procedural knowledge - how conceptual knowledge is put to use.

3. Operational knowledge - how conceptual and procedural knowledge are used to react in the appropriate way to real communicative situations

\subsection{The Student Model}

The Student Model encompasses both a statement of learning goals and an assessment of student' skills. Goals are ranked according to intrinsic grammatical difficulty levels, which in our system are graded up to six levels - in turn levels are organized on the basis of Council of Europe report CC-LANG (96) 13 rev. by B.Page (1996). The student's skills may also be graded from Basic (A1) up to Grade Six (C2) where each skill may be assessed separately and receive a different type of evaluation. According to the student's performance in placement or entry tests, and to his statement of learning goals, his Model will be constructed from the Tutor and an Ideal Curriculum or Learning Path shown to the student. The ideal learning path includes all activities organized as a sequence of tasks and a number of milestones, depending on the learning goals. In turn, learning goals may be stated in two different modes: Mode 1 allows the student to access and highlight a number of different communicative functions, which in turn will automatically address grammatical, lexical, semantic and pragmatic goals as exemplified in audiovideo learning units. Mode 2 allows the student to choose one of six grades where each one again addresses a number of communicative functions regarded as the 
3-Delmonte-209-234-x 4/11/02 5:09 pm Page 7

Feedback generation and linguistic knowledge in SLIM

most adequate for a certain level of knowledge of the language (see Figure 3). Communicative functions have been previously ranked manually and appropriate labels have been applied to the corresponding utterance - see Section 4 for a detailed explanation of the process.

\subsection{The Language Tutor}

As discussed above, the Language Tutor is The Supervisor and has access to all components. It also has two special components: the Pedagogical Component and the Linguistic Knowledge Database (LKD). Before discussing in some detail the contents of these components, we shall outline the interactive part of the system. After the student has taken a test for entry level evaluation or for assessment purposes, the Tutor creates a Student Model which is made up of personal information from the student, and a Learning Path. Every subsequent action on the Model is intended as some form of update of the Learning Path. Any update action is motivated by the Pedagogical Component and by the intervention of some form of warning or advice from the Help Component.

By accessing the LKD the Tutor creates the Ideal Learning Path which will be subsequently updated whenever the student enters the system and engages in an exercise. Assessment is done locally by each individual didactic module making up some specific linguistic activity. Also, the Pedagogical Component has the further task of evaluating students' performance with reference to his/her learning path, in order to execute any adjustment. Adjustments may be of two kinds: task deletion and task addition. Every time an adjustment takes place, the Tutor may have to issue a message to praise or to advise the student.

The LKD is then activated by the Tutor every time the student completes exercises in one of the modules of linguistic activities contained in the learning path. The students' performance is assessed in real time according to type and mode of execution of the exercise. The student may decide to repeat the same exercise as many times as he likes, and iterative assessment will take place. As soon as the student leaves the module, the Tutor is called

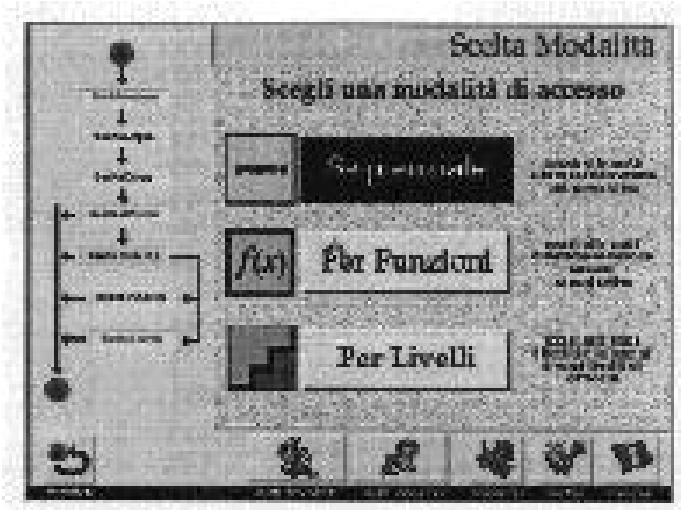

Fig. 3. Choice of access modality. 
and a list of results are passed for global evaluation. Help facilities are embodied from two hypertexts: a Grammar, and a Phonetics course; all help messages are built around them. By matching the linguistic content of the exercise with the LKD and by computing repetitions and performance over all time, a total proficiency mark will be issued.

The Tutor reasons according to Macrolevels, as explained in Section 4.1, and updates the learning path if needed. In turn Macrolevels refer to single specific items contained in the LKD by connecting to Microlevels and to Phonetics while at the same time having capabilities related to overall learning goals.

\section{Students'skills and inventory of linguistic items}

Knowing a foreign language is a process that involves all the student's communicative skills. In particular it addresses:

(a) passive abilities like understanding spoken and written linguistic messages;

(b) active abilities like writing and speaking in the target language.

In other words, these abilities may be further broken down into their basic constituents:

- acquisition of a base lexicon made up of a certain number of words;

- acquisition of the basic grammar rules and grammatical words;

- acquisition of the basic syntax and semantics;

- acquisition of the phonetics, phonology and prosody.

In addition, all these learning items must be transposed into a basic communicative environment in which the language must be adequately coupled to cultural issues and knowledge of the world related to the target language.

Supposing now we make a list of linguistic items, be they lexical items, grammatical items, grammar rules, syntactic and semantic structural rules, phonetic and phonological rules as well as morphophonological and prosodic rules of the language. These items have been organized into six levels of difficulty, determined both by objective and by criteria derived from Contrastivity Theory. The task of the automaton would be that of supervising the transition from one level to the other, once the entry level of the student has been ascertained by objective placement tests. The automaton will use achievement and proficiency tests during the course in order to establish the increase in proficiency achieved by keeping a record of all the previous lessons and tests carried out by the student.

We refer ourselves to the ESU Framework which introduces a yardstick for different types of linguistic performance scales according to language use and skill. In this case, our course will address the first four levels in a ladder made up of nine levels. We assume that this last level is adequately addressed by an advanced course, whereas an intermediate course in English will suitably address levels 4 to 6 . So we definitely refer to the Guide prepared by Page (1996).

\subsection{Topics, communicative functions and semantic notions}

The student will enter the course from main topics which in turn may be broken down 
into communicative functions and semantic notions. Functions may belong more naturally to one or the other topic, thus cutting vertically the list of contents of a course; on the contrary, semantic or conceptual notions cut each topic horizontally. The same applies to grammar rules which could be assigned difficulty scores according to an evaluation metric which is commonplace amongst language teachers (however see the list below), thus dividing up the grammar rule universe into levels; at the same time, these rules might be scattered at random amongst topics and be independent of the topic the student is currently learning.

Asimple and cursory listing of typical survival or general syllabus in a course for foreign language learners includes all or part of the following themes or topics:

1. Personal Identification;

2. Finding a house, flat, room;

3. Trade, job, profession, occupation;

4. Hobbies, entertainment, free time;

5. Travel, traffic, taxis, automobiles;

6. Interpersonal relations and social conversation with friends, family, colleagues differing in degrees of authority;

7. Health and welfare - relating to public structures like hospitals, physicians and chemist's shops;

8. Education in schools and universities;

9. Shopping and supermarkets;

10. At the restaurant, foods and drinks;

11. Public transport, postal service;

12. Visiting tourist places in Italian cities;

13. Discussion about the weather.

Suppose now we start up by regarding some communicative functions as being intrinsically more pragmatically relevant, we shall end up with a ranked list as follows:

1. Describing actions: habitual, future, current, past;

2. Information: ask for, indicate something/someone, denoting existence/non existence;

3. Socializing: introduce oneself; on the phone;

4. Expressing agreement and disagreement;

5. Concession;

6. Rational enquiry and exposition;

7. Personal emotions: positive, negative;

8. Emotional relations: greetings, sympathy, gratitude, flattery, hostility, satisfaction;

9. Categories of modal meaning, scales of certainty: (i) impersonalized: affirmation, certainty, probability, possibility, negative certainty; (ii) personalized: conviction, conjecture, doubt, disbelief; (iii) scale of commitment; (iv) intentionality; (v) obligation;

10. Mental attitudes: evaluation; judgement; committal; release; approval; disapproval; persuasion; inducement; compulsion; prediction; tolerance. 
We worked on three levels of specification and representation:

- Database level, where each utterance is associated to a microfunction (122 microfunctions);

- Topic-function interface, where each microfunction is associated to a (survival) topic;

- Higher interface level, where access in self-directed mode may be achieved through eight macrofunctions;

- Automatic tutor interface, where each microfunction may be chosen according to a level on a graded scale of four according to grouping of communicative functions into interpersonal communicative acts highly reminiscent of Halliday's (1970) proposal.

All these communicative functions have been given a compact organization within the following six more general functions or macrofunctions (see Figure 4):

1. Ask; give, offer, consent;

2. Describe; inform;

3. Socialize.

4. Assert, say, reply;

5. Express emotions, modalities;

6. Mental attitudes;

Each such macrofunction may contain further specifications in the sense indicated above. In the communicative based approach to language learning, what comes first - as Level 1 - should be related to communicative activities that usually come first in real life situations. For instance, before starting a conversation people exchange greetings, and so on. However, we may assume that the ranked list above should be regarded as a functionally relevant subdivision of tasks, which however could be interleaved with situations at all levels. The ranking thus can be used as a simple subdivision into difficulty rating, from the less to the more difficult to learn.

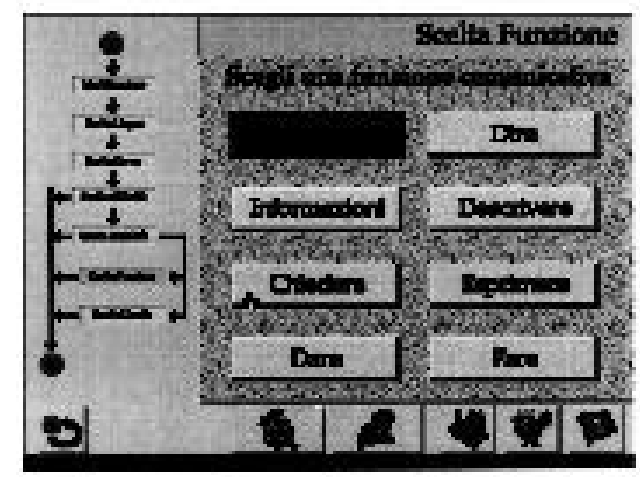

Fig. 4. Choice of macro-communicative function. 


\subsection{Language skills and macrolevels}

- MACROLEVEL I

This should be regarded the basic level of knowledge of $\mathrm{L} 2$ at which learners shall be able to intervene productively in the simplest communicative situations. They shall be able to use the morphosyntactic structure specified below, and shall understand texts both oral and written, with the lexicon included in the base vocabulary.

i. $\quad$ Listening

Recognize the phonemes of L2, make syllabic segmentation of phonic chains, recognize main intonative-syntactic profiles. Understand simple oral messages related to simple communicative functions, recognize predictable questions and follow simple instructions.

ii. $\quad$ Reading

Recognize graphic and orthographic structure of word forms; recognize individual words, street names, public signs, shop names; read and digest information at simple sentence level - one sentence at a time. Read word by word from beginning, cannot predict or vary pace. Read at sentence level, and digest each sentence before going to the next. Can work with familiar forms, notices, work sheets.

iii. Metalinguistic competence

Recognize and name elementary structural elements of L2, make analysis, synthesis and transformation of linguistic structure at morphological, phonological, lexical, and syntactic level.

iv. Writing

Complete forms which require one word or simple 'stock phrase' answer. Write name and address and a few personal details, some numbers. Fill in forms, work sheets, about own work. Complete appropriate forms using one verb sentences. Produce the odd question when most of the information is supplied by the situation. Produce a very few memorised questions about time, person, and place. Produce simple yes/ no or 'wh' question forms. Describe job in short phrases, give straightforward directions, instructions in memos or standard format.

v. Speaking

Know a number of words and phrases. Exchange the odd word or phrase but have no meaning exchange outside the situation. Limited by poor production. Give personal information, express personal likes, dislikes, preferences, opinions; describe job and give instructions.

\section{- MACROLEVELII}

Learners acquire greater self-assurance and self-consciousness of previously learned materials, as well as increase their ability to intervene actively in much larger communicative situations both in oral and written skills. Increase proficiency in the socio-cultural aspects of L2.

\section{i. $\quad$ Listening}

They can understand reports on simple events and actions in the past; expressing doubts, or hesitations. 
R. Delmonte

\section{ii. $\quad$ Reading}

See simple relationships showing cause, effect and simple conditions. Cope with short memos or letters but not with anything longer; recognize relevance at paragraph level and vary pace accordingly; extract factual but not logical or implied information, understand each point of argument but often fail to see connections.

iii. Metalinguistic competence

Recognize and name structures included in the list above, recognize different genres of texts, make complex operation of analysis, synthesis and transformation of linguistic structures.

iv. Writing

Produce individual stock questions, one at a time; make standard enquiries of a routine, impersonal nature; describe functions of posts, processes, procedures in simple language; write routine standard letters in answer to simple queries. Write stock letters or memos of apology, assurance, promise; make arrangements for meetings, check or cancel appointments.

v. Speaking

State position in very broad terms; function in shops, hotels, travelling, and exchange personal details; discuss aspects of work and immediate working environment; make appointments, arrangements, check, cancel, alter; present oneself, make introductions, invitations, make acceptances or refusals over meals.

\section{Spoken language modules}

We shall only concentrate on oral activities and amongst these on those requiring feedback from the computer. In this way we shall not present audio-active comparison, dictation and other exercises which require self-monitoring and self-assessment.

Phonetic exercises focus on phonemes that cause users the most difficulty. Phonemes have been divided between consonants and vowels, and graded for difficulty on the basis of contrastivity criteria - those phonemes which do not exist in L2 are graded as most difficult. We have created a hypertext which accesses each phoneme and gives help to the student in difficulty. Each phoneme is accompanied by a video clip with the front vision of a native speaker's mouth while pronouncing it.

Once the system has identified the users'phonetic problems, they will be able to select from their own list of items to practise. These can be induced by typing in the mispronounced word and The Supervisor will choose the appropriate phonetic area to work on (see Figure 5, where all the various components of the students'interface are shown).

\subsection{Exercises on contrastive phonemes}

These exercises are aimed at developing users' confidence in different types of phonemes existing in the various languages through a contrastive analysis of Italian and the foreign language which they are learning. Exercises are based on a dictionary mapping that considers the difficulty level of the phonemes of the foreign language in relation to Italian phonemes.

Phonemes are therefore divided into classes of different difficulty levels. These exercises treat the various phonemes in sequence of increasing difficulty; thus, they will start 


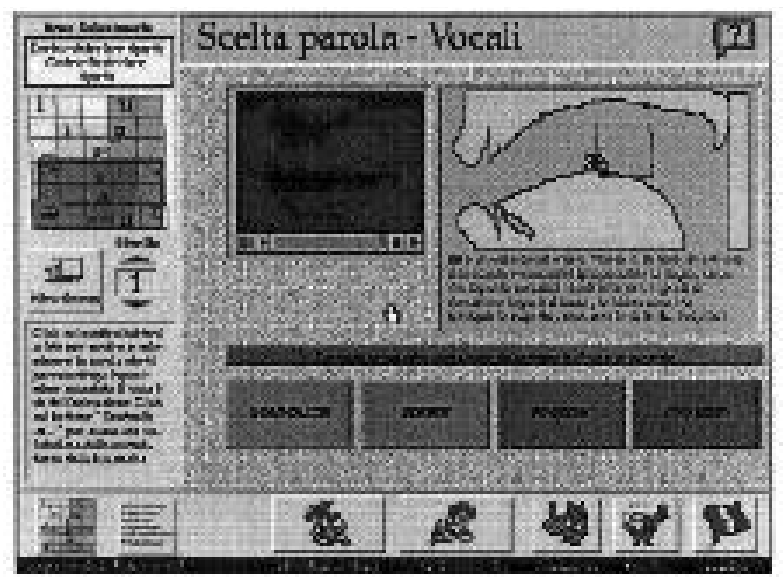

Fig. 5. Choice of phonetic activity.

with phonemes that present fewer problems for the Italian speaker, and will end with the most difficult ones.

The exercises that have been proposed are of three kinds:

- the first one focuses on the perception and correct identification of a given phoneme from a set of four phones chosen at random by the computer from amongst a cluster of phonemes belonging to an easily confusable set, and according to a given scale of difficulty;

- the second one requires the student to identify the tonic phoneme of the word that is proposed, again from a set of four;

- the third one relates to the difficulty involved in uttering the phonemes of a whole single word, i.e. the difficulty resulting from the sum of all the difficult aspects of each phoneme that are composed within the proposed word.

In every exercise the system proposes words randomly, selecting them according to their levels of difficulty. Users can decide for themselves to move on to the subsequent level of difficulty. In each exercise it is possible to record one's own voice and compare it with the master's (Repetition Exercise) and also to activate the Speech Recognition mechanism that allows users to evaluate the correctness of the pronunciation (see Figure 6 , where all the various components of the students'interface are shown).

\subsection{Minimal pairs}

The display that presents the minimal pair exercises is designed so that the two columns of words with contrastive phonemes appear in opposite lists.

Users will first listen to the left-hand column, displaying words with the same phoneme. They will be free to record their voice while repeating the single phonetic units and then compare it with the master's. Later users will listen to the right-hand column that displays words containing the contrastive phoneme. If they wish, users can 


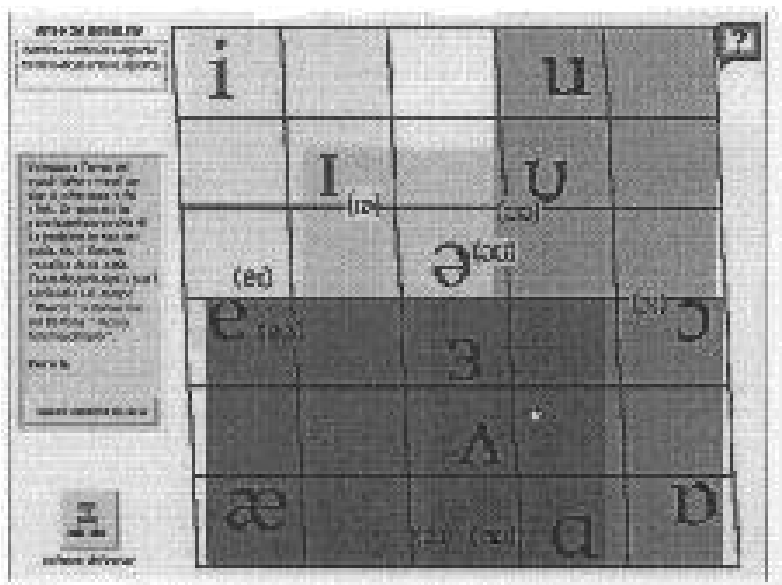

Fig. 6. Vowel electronic map with colours individuating phonetic areas.

also record their voice while reading the second column and compare it with the master's.

Finally, users will listen to the minimal pairs, i.e. the pairs of words that differ only for the two contrastive phonemes. Users then can record their utterances, by reading and comparing each pair with the master's.

\subsection{Minimal pairs recognition}

In another phonetics exercise (see Figure 7), the system recognizes the minimal pairs users are pronouncing. The system offers a minimal pair which they have to produce orally. Subsequently, the system transcribes the users' performance and checks its correctness.

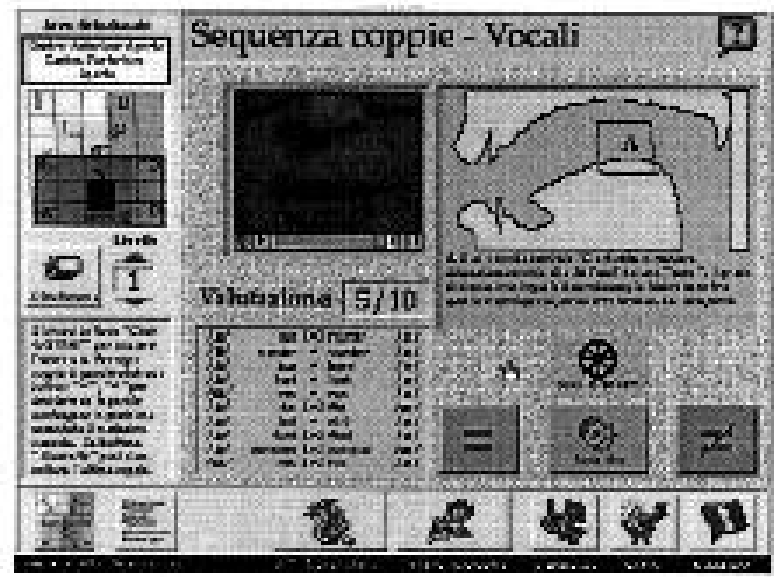

Fig. 7. Minimal pairs exercise. 


\subsection{Grapheme-to-phoneme exercise}

In this exercise the system displays a set of words that are similar in terms of spelling. Users choose a word corresponding to the one that the system is proposing orally.

This exercise is made possible through the Soundex application program that calculates the graphemic similarity of words and randomly proposes those words which graphically resemble the closest words users are listening to.

\subsection{Phoneme-to-grapheme exercise}

This exercise presents similar features to the previous exercise. In this case, the system displays a series of words that have been chosen for their phonetic, and not graphemic similarity. Users choose the word corresponding to the one the system is presenting orally.

The system selects the proposed words considering the phonetic characteristics of each word. This is possible due to the word classification present in the database, which has been created on the basis of the phonetic transcription of each word.

\subsection{How SLIM copes with prosody}

The most interesting part of the system regards exercises in prosody. It is a fact that in all second language learning activities, prosody plays an important role. We can think of it as being related to two main tasks: saying the appropriate words/sentence and saying one word/sentence in the most appropriate way. The first task is a communicative functional task which is related to speech recognition; the second task is a phonetic task which can either be a phonemic or a prosodic task. Aphonemic task requires the learner to produce the right sound in a given context - this sound is more difficult the more contrastively distant it is from L1 phonemes inventory. A prosodic task requires the learner to produce a linguistic unit like a word, a phrase or a sentence in a qualitatively comparable way with a master specimen provided by the system.

In both cases, the second task is performed by means of a comparison between a master and a student signal. In addition, prosodic constraints can be applied on the student signal from a contrastive perspective: according to phonological properties of a given language or family of languages some acoustic parameters can be disregarded or highlighted when needed.

In particular, we assume that there are at least three different families as far as prosodic properties are concerned. Family-1 languages: stressed-timed languages like English which allow for compensatory shortening of unstressed syllables, phonemic modification into schwa sounds of unstressed vowels, assimilations, elisions and other similar phenomena. Family-2 languages: syllable-timed languages in which syllable duration and amplitude vary according to whether they are stressed or unstressed but no marked compensatory effects are detectable, like Italian, French and also Japanese. Family-3 languages: like Chinese and other Sinitic languages in which tone is an important phonemic feature and duration may also play a phonemic role. Acoustic correlates of prosodic phenomena can thus be tuned and taken care of according to constrastive aspects. 


\subsection{Exercise on word-stress}

This exercise, as the one on intonation presented below, is based on a program 'Prosodics' created at the Laboratory of Computational Linguistics of the University of Venice with the contribution of research fellows from the University of Iasi in Romania.

The Prosodic Module allows the student to listen to each word making up the exercise both as it is spoken by the Master and in a segmented version: phonetic segmentation is automatically performed on the original digital speechwave by the system in order to allow the student to listen to each phone as it has been really spoken in the actual word context. The same word can be listened to in a syllabic segmented mode: in this second mode, the system performs the same segmentation at phone level. Subsequently, phones are joined together according to rules of syllabic phonology. Again, the student is presented the same word syllable by syllable, where each segment is constituted by the actual syllables being spoken by the Master in the original speechwave.

The aim of this exercise is to make foreign-language learners feel more confident with the peculiar characteristics of word-stress in the target language. In particular, the exercise draws users' attention towards the position of word-stress and the longer the word, the more difficult it is to guess the right position of the stress. Word-level exercises are basically concentrated on the position of stress and on the duration of syllables, both stressed and unstressed. In particular, Italian speakers tend to apply their word-stress rules to English words, often resulting in a completely wrong performance. They also tend to pronounce unstressed syllables without modifying the presumed phonemic nature of their vocalic nucleus preserving the sound occurring in stressed position: so the use of the reduced schwa-like sound [ $]$, which is not part of the inventory of phonemes and allophones of the source language, must be learned. The main activity window (Figure 8) for Sillabe Atone (unstressed syllables) is divided into three main sections: in the higher portion of the screen the student is presented with the orthographic and phonetic transcription (in Arpabet) of the word which is spoken aloud by a native speaker's voice. This section of the screen can be activated or disactivated according to which level of Interlingua the student belongs to. In particular, the stressed

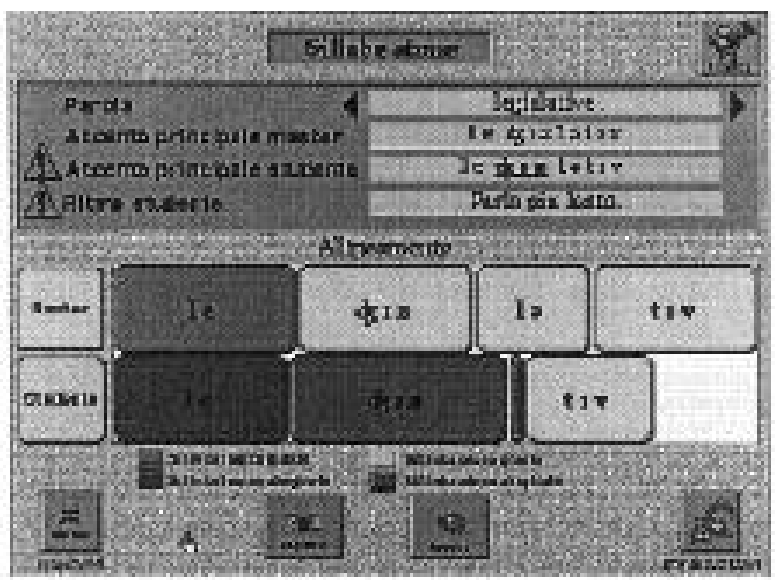

Fig. 8. Unstressed syllable exercise. 
syllable is highlighted between a pair of dots. The main central portion of the screen contains the buttons corresponding to each single syllable which the student may click on. The system then waits for the student performance which is dynamically analysed and compared to the Master's. The result is shown in the central section by aligning the student's performance with the Master's. According to duration computed for each syllable the result will be a perfect alignment or a misalignment in defect or in excess. Syllables exceeding the Master's duration will be shown longer, whereas syllables shorter in duration will show up shorter. The difference in duration will thus be evaluated in proportion as being a certain percentage of the Master's duration. This value will be applied to parameters governing the drawing of the related button by HyperCard ${ }^{\mathrm{TM}}$. At the same time, in the section above the central one, two warnings will be activated in yellow and red, informing the student that the performance was wrong: prosodic information concerns the placement of word stress on a given syllable, as well as the overall duration. If the student practising at word level makes an error, s/he will hear an unpleasant sound which is then followed by a visual indication of the error by means of a red blinking syllable button, the one in which s/he wrongly assigned word stress. This is followed by the rehearsal of the right syllable which always appears in green. A companion exercise takes care of the unstressed portion/s of the word: in this case, the student will focus on unstressed syllables and errors will be highlighted consequently in that/those portion/s of the word. Finally the bottom portion of the window contains buttons for listening and recording on the left, arrows for choosing a new item on the right; at the extreme right side a button to continue with a new Prosodic Activity, and at the extreme left side a button to quit Prosodic Activities.

In Utterance Level Prosodic Activities the student is presented with one of the utterances chosen from the course s/he is following. Rather than concentrating on types of intonation contours in the two languages where performance-related differences might result in remarkable intraspeaker variations, we decided to adopt a different perspective. Our approach is basically communicative and focuses on a restricted number of communicative functions from the ones the student is practising in the course s/he is following. ${ }^{1}$ Contrastive differences are thus related to pragmatic as well as performance factors.

\subsection{Exercise on intonation}

The program that takes care of prosodic or suprasegmental features of speech has been organized as a pitch-tracker which can use the segmentation of the Master signal, which can be a syllable, a word, a phrase or a sentence, that come with a complete phonetic transcription, and compare it in real time with the student's voice as s/he records it. Prosodic exercises call this application which uses the following tagging conventions to encode the signal's main features:

A. regarding pitch level:

W - very low $\quad(60-100 \mathrm{~Hz}$ for men, $140-180 \mathrm{~Hz}$ for women);

\footnotetext{
${ }^{1}$ For a different approach see Ueyama (1997) on Japanese-English.
} 
R. Delmonte
$\mathrm{L}-$ low
(100-140 Hz for men, 180-220 for women);
$\mathrm{M}$ - medium
(140-180 Hz for men, 220-260 for women);
$\mathrm{H}$ - high
(180-220 Hz for men, 260-300 for women);
$X$ - very high
(220-260 Hz for men, 300- 340 for women);
$\mathrm{Z}$ - extremely high
(260-300 Hz for men, 340-380 for women);

B. regarding pitch movements:

$$
\begin{aligned}
& \mathrm{S} \text { - level (stationary) } \\
& \mathrm{R} \text { - raising } \\
& \text { / - sharp raising } \\
& \mathrm{F} \text { - falling } \\
& \text { I- sharp falling }
\end{aligned}
$$

C. regarding loudness movements:

* - local maximum;

\# - local minimum;

! - absolute maximum;

? - absolute minimum;

+- raising;

- - falling.

In addition, we can use an absolute value in ms for the duration of each pitch segment. The tool has shown its potentialities for utterance individuation and comparison; we are now applying it to the syllables and words of tone languages like Chinese and the results are very promising.

Among the advanced activities this exercise plays an important role in improving the prosodic aspects of oral production. In particular, it deals with intonation and is thought to help learners to pay attention to the various intonation characteristics used in sentences with different communicative functions. Users are asked to produce the proposed sentences with an intonation as close as possible to the Master's. The system then compares users' performance with the Master's. This comparison can take place due to the close relation between the communicative function of the sentences and their intonation.

In this phase, the system works on single parts of the sentence by associating them with segments which are relevant from the intonation point of view. This comparison enables them to identify those parts that have been performed incorrectly. Then the system highlights those parts with an incorrect intonation contour, giving some suggestions on how to improve the performance and eventually invites users to try again, focusing exclusively on the part to be corrected. Thus, the system supplies users with good feedback and they can autonomously and effectively improve their oral performance, within the self-learning environment (see Figure 9).

\subsection{Choose an answer}

This is one of the most interesting activities because it joins together speech recognition, the ability of choice at a textual level and oral production, in a pleasant and stimulating way (see Figure 10). 


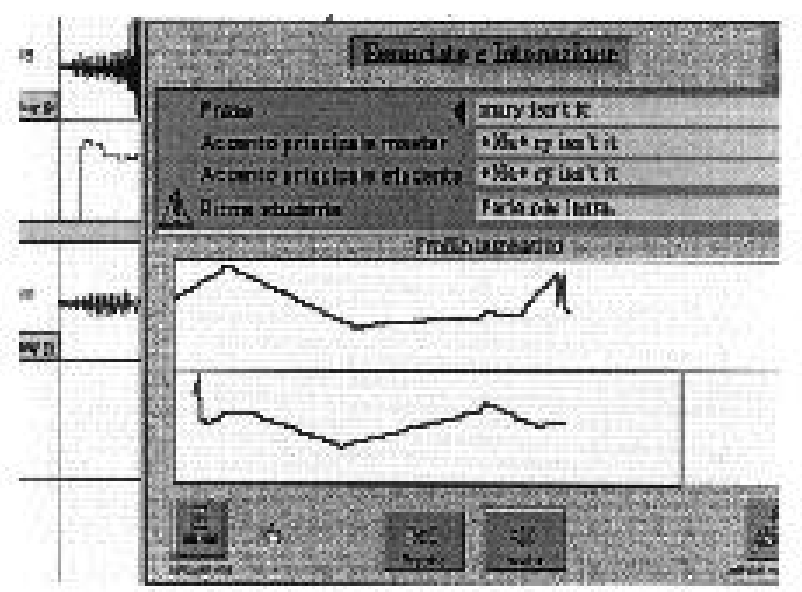

Fig. 9. Intonation exercise.

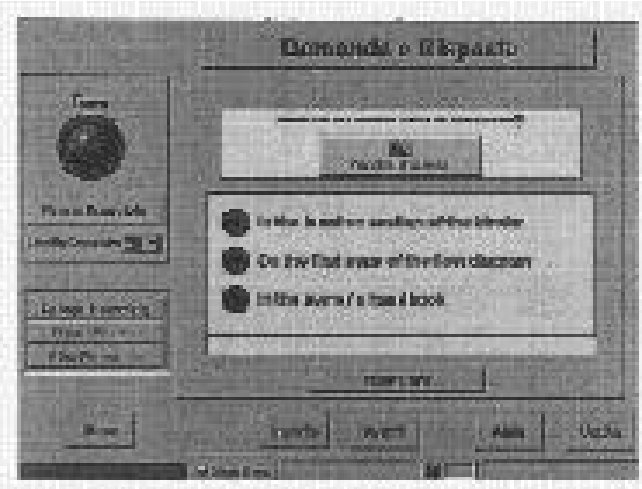

Fig. 10. Question answering.

Users listen to a question that the system selects from those available in the database. Users listen to the question twice and then select from three answers that appear on the screen, drawn from the database. Users have to select the most appropriate answer for the kind of question they have just heard, within the time given and, once they make their choice, they produce it orally. The system activates the speech recognition mechanism that can give different responses.

If the user's utterance is not clear and correct, the speech recognition module informs them and invites them to try again.

If the use's performance is qualitatively good but the answer is incorrect, they are asked to listen to the question again and choose the right answer.

Eventually, if users select the correct choice and produce it correctly, the system will respond to the good performance and they will be able to move to the other questions. The aim of this activity is to direct the user towards a more realistic usage of language. 


\subsection{Role-play}

This activity has the objective of testing the student's proficiency in the communicative functions of L2. The system has access to all dialogues and to each utterance thereof via the communicative function it expresses. Students will have to listen to the complete clip, paying great attention to the particular role that each will have to act out. Each videoclip has been carefully manipulated and visual markers have been added in order to warn the student that they should pay attention to the following turn in the dialogue.

On a later occasion, each will listen to the clip without the utterances which they themselves will have to make. They will have to be ready to interact with the text by correctly pronouncing the missing expressions. To make the activity more authentic, learners will only be given enough time to utter the correct expressions as in a normal dialogue.

We have devised three different modes of execution of this important exercise (see Figure 11):

1. Slow interaction: in this mode it is possible to stop the videoclip in the portion of dialogue to be spoken by the student; different interruption times are allowed. Feedback is always provided: as the available time is about to elapse, the student will listen to the actual utterance to be spoken by the current speaker in the videoclip.

2. Cute interaction: no feedback is provided in this second mode and the videoclip can only be slowed down.

3. Real interaction: no feedback, no slowing down or interruption available. Speech recognition takes account of the student's performance.

Speech recognition allows the computer to give immediate feedback to the student. However, the student will be given feedback only at the end of the videoclip. Students may use the same expressions as the original or different ones, as long as they express the same linguistic content or communicative function.

In addition, users will also be able to activate the automatic prosodic supervisor and through this it will be possible to evaluate the correct rhythm and correct intonation pattern, as well as the position of sentence accent.

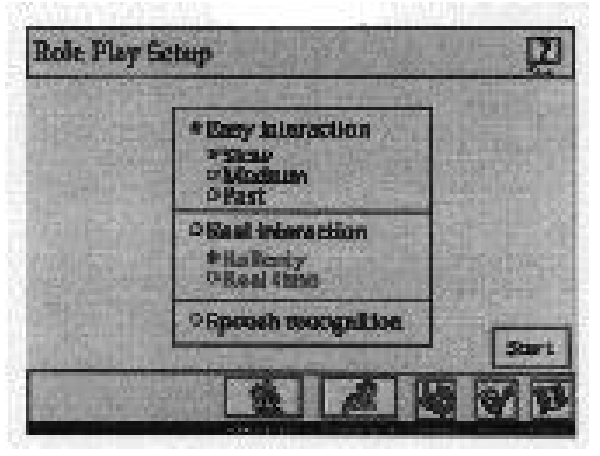

Fig. 11. Role play exercise. 


\section{Assessment, evaluation and feedback generation}

Generally speaking, assessment in self-instructional courses is problematic but very important. Self-assessment can be used for appropriate testing purposes - to provide feedback information, diagnostic testing, and placement testing. Within learner-centred selfinstruction, or self-directed learning, self-assessment is a necessary part. Decisions about whether to go on to the next item, exercise or unit, decisions concerned with the allocation of time to various skills, decisions concerned with the need for remedial work, are all based on feedback from informal and formal assessment. This concept then is central both to the learners'personality and to the kind of courseware we are building. We consider it important as an educational goal in its own right, and training learners in this is beneficial to learning.

In fact, language learners regularly engage in self-assessment as part of their learning. They do exercises and check, by whatever means available, whether their responses are correct or not. They check the computer's comprehension of their spoken language, and adjust it when necessary. To check oral production, the computer is equipped with the appropriate speech recognition system which is part of the PlainTalk ${ }^{\mathrm{TM}} \odot$ system by Apple, but it may be constituted by any other speech recognition device available on Windows-based platforms, like ViaVoice ${ }^{\circledR}$ by IBM or Dragon Naturally Speaking ${ }^{\circledR}$ by Learnout \& Hauspie ${ }^{\mathrm{TM}}$ systems.

Self-monitoring is also part of the course: to mimic audio-active comparison while listening to and watching video clips, learners are required to check their performance against the model. To improve the ability to self-monitor, all oral exercises have some form of visual feedback. For instance in the exercise shown in Figure 11, students are asked to listen to the oral rehearsal by a native speaker of the single utterances making up the dialogue of the current video-clip, and these are shown on the left side of the students' interface; after that they can try to match each letter with the number corresponding to the written version of the same utterance. If the match is right they will hear again the spoken utterance and a green blinking light will confirm the right choice; if the student makes a mistake, a red light will blink, then the right connection will be shown and the right utterance will be spoken aloud.

In a language like English, the ability to perform a complete phoneme-to-grapheme translation in L2 is severely undermined by its phonotactics which is full of exceptions and requires a lot of exercises to couple understanding and orthographic abilities. Clearly, a much harder task is encountered by students of oriental languages like Chinese and Japanese, where a completely new sign system has to be learned from scratch. As for written language skills, the number of assessment tools is fairly extended and they are based essentially on the knowledge the computer has of every single linguistic item considered in a given task. For instance, if the AT is assessing the learners' achievements in grammatical knowledge, it accesses the LKD where each item may correspond either to a word-form, or a syntactic phrase for syntactic tests; or to an utterance for context-based pragmatic and communicative function tests (see Delmonte, 1995).

The LKD is the foundation for all drill construction, and thus it constitutes the backbone of all self-assessment activities as well as those of the AT. In particular, the AT may create an infinite number of drills automatically, since it has been given an internal pedagogical and linguistic set of criteria on the basis of which it may choose at random from the LKD the items relevant and adequate for any given linguistic task. 
The AT has also been equipped with a number of tools that enable it to check and spot mistakes whenever they are made by the learner, and keep a record of them. Errors may be noted in both oral and written activities, and will be simply notified to the student in Free Mode or communicated by the AT when working in Guided Mode.

In all cases, learners will be informed about the error, the kind of error they produced, the possible reason why they made that kind of error: as a side-effect, they will be directed to carry out some linguistic activity appropriate to help remedy that problem, or else the grammar section on that item will be shown. The same will happen with phonetic problems: if the performance scores too low, the phonetics hypertext will be called and presented to the student at the appropriate item.

After taking a placement test the student is assigned to a Macrolevel. Suppose our student is placed in Macrolevel 1, the AT will try to individuate the Microlevel from the six available according to constraints imposed on each level. Objectivizing such constraints in the linguistic materials presented to the student while working with SLIM requires a further important step: assigning scores.

Scores are assigned for each main activity at every level of linguistic description: from phoneme to utterance level. In particular phonemes are graded according to contrastivity criteria as well as to perceptual discriminative ones. Words receive a cumulative score according to their inherent phonetic grade of difficulty. Words are also addressed at grammatical level in order to be assigned scores: functional words receive a higher score than content words, and amongst these irregular ones have a still higher score. Structural scoring is computed at utterance level and takes into account intrinsic syntactic complexity in terms of number of constituents, number of embeddings, whether its constituents are argument or adjunct. All the low level scoring adds up to the functional scoring already assigned at utterance level, ending up with a final computation which is evaluated and weighted by the AT.

\subsection{Feedback generation}

However, the real problem to cope with is interaction with the student in a way that reflects both the outcome of the evaluation procedure and a strategy that takes into account the student personality as a whole. Also, it is not clear what type of feedback is most appropriate for a self-tutoring system like the one we have presented. Below is the typology of feedback as listed by Lyster \& Ranta (1997):

- Explicit correction: the explicit provision of the correct word or part phrase, usually making clear that this is a correction - e.g. you mean..., you should say...

- Recast: the teacher's reformulation of all or part of the student utterance, minus the error, without making it clear that this is a correction.

- Clarification request: What? What do you mean? (only coded in response to language error).

- Metalinguistic feedback: comments, information or questions regarding the well-formedness of the student's utterance, but without giving the correct form: that's not quite right, is that right?, problema is masculine.

- Elicitation: getting the student to give the correct form by pausing for her to continue the sentence, or by asking the student to reformulate the utterance. 
- Repetition: the repetition, in isolation, of the student's utterance, usually with error intonationally marked. (This was found to co-occur with all other types of feedback.) In addition, $38 \%$ of student errors received no correction from the teachers.

Lyster and Ranta evaluated these strategies by looking at what happened in the turns immediately following the provision of feedback: Did the student try to correct her previous utterance? Was that reformulation correct, and was the correct form initially suggested by the student concerned, or by the teacher or another student? They found that Recast, the most commonly used form of feedback, had the lowest rate of uptake (students tried to correct their previous utterance in $31 \%$ of cases, with about half of the reformulations being correct). Explicit Correction had a good rate of correct student reformulations, but, due to the form of feedback, the correct forms were always generated by the teacher, rather than the student. The use of Elicitation always required the student to attempt to generate the correct form themselves, and as such produced the highest rate of correct student-generated repairs. Although Metalinguistic Feedback had a lower rate of uptake overall, a similar proportion of the attempted reformulations were correct.

From the point of view of the activities implemented and their internal structure, we assume that apart from Elicitation and Repetition all the remaining strategies are potentially available for the generator of feedback. However, Explicit Correction would work with a good level of confidence only with written rather than with spoken exercises, due to the high number of false positives and false negatives usually occurring with Automatic Speech Recognition devices in general. We also regard the Clarification request as a strategy especially suitable for human tutors, requiring the appropriate tone of voice and accompanying gestures, something which is not easily reproducible in an automatic tutoring context. In sum, Recast and Metalinguistic Feedback are the two strategies which best fit into our system and in general whenever automatic evaluation tools are being used; this would apply equally to spoken activities which rely on ASR (Automatic Speech Recognition) and Prosodic Tutoring, and to written activities.

\subsection{Evaluation and lessons learned}

Preliminary evaluation of the system has been conducted under various controlled schemes. We chose students from Economics to evaluate oral skills at a Beginner's level; to evaluate written abilities we chose students from courses of Foreign Languages and Literatures. We discovered that the system needs a lot of tuning in order to correctly individuate and assess each single student in order to build the appropriate Student Profile. All students then answered a questionnaire concerning the use of the system which allowed us to improve interaction: in some cases, with written abilities, we were told that grammatical drills were too simple for the majority of the students involved. This was due to the fact that they were produced automatically with a given typology in mind, and difficult typologies required algorithms which were too complex to be set up. This survey was done on small group of students. We came up with a number of Guided Path self-contained packages which constitute a first solution to some of the open problems we were asked to face. Each package of Guided exercises constitutes a closed set which has an internal self-consistency determined by a number of parameters. These 
parameters can be used in a very strict manner or they can be relaxed, thus obtaining an adaptation to different students'profiles; they are:

- $\quad$ execution time for each type of exercise

- $\quad$ error count for each type of exercise

- number of times the exercise may be repeated

- $\quad$ overall execution time for the package

- overall error count for the package

On a first check we received a favourable impression from the students involved. We show (in Figure 12) the interface screen for the authoring of Teaching Units for Guided Exercises, where we see the list of activities in the middle section, and in the lower section the two slots available for the tutor to decide the time assigned to each activity and the number of repetitions. Asimilar interface would be available for the Unit as a whole. The output would be a package which contains pointers to SLIM Activities with an adequate interface for the student.

\section{References}

Ahmad, K., Corbett, G., Rogers, M. and Sussex, R. (1985) Computers, Language Learning and Language Teaching. Cambridge: Cambridge University Press.

Alderson, J. C. and North, B. (eds.) (1991) Language Testing in the 1990s. London: Modern English Publications with The British Council.

Alderson, J .C. and Windeatt, S. (1991) Computers in language testing. In: Alderson, J. C. and North, B. (eds.), Language Testing in the 1990s. London: Modern English Publications with The British Council.

Allinson, L. J. and Hammond, N. J. (1990) Learning support environments: rationale and evaluation. Computers and Education 15: 137-143.

Ambron, S. and Hooper, K., (1990) Learning with Interactive Multimedia. Redmond, WA: Microsoft Press.

Apple Human Interface Guidelines: The Apple Desktop Interface, (1987) Reading, MA: AddisonWesley.

Bacalu, C. and Delmonte, R. (1999) Prosodic Modeling for Syllable Structures from the VESD Venice English Syllable Database, in Atti $9^{\circ}$ Convegno GFS-AIA, Venezia.

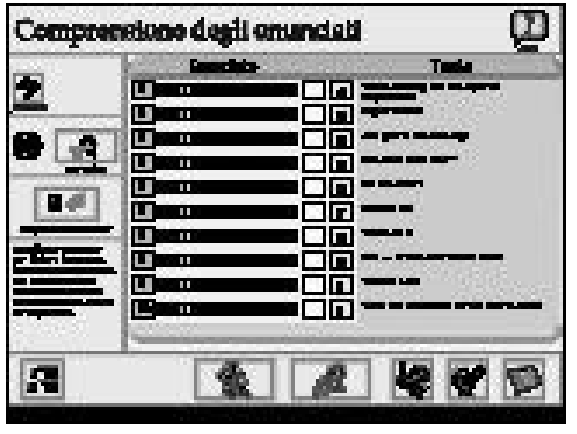

Fig. 12. Utterance understanding and orthography decoding practice. 
Carroll, B. J. and West R. (1989) ESU Framework, London: Longman.

Davies, A. (1990) Principles of Language Testing, Oxford: Blackwell.

De Corte, E., Lodewijks, H., Parmentier R. and Span P. (eds.) (1991) Learning and Instruction. Oxford: Pergamon.

Delmonte R., and Greselin F. (1995) How to create SLIM courseware. In: Yeow Chin Yong and Chee Kit Looi (eds.), Proceedings of ICCE '95, Singapore, pp. 206-213.

Delmonte R. (ed.)(1995) How to create SLIM courseware - Software Linguistico Interattivo Multimediale, Padova: Unipress.

Delmonte R. and Stiffoni,F. (1995) SIWL - Il Database Parlato della lingua Italiana, Convegno AIA - Gruppo di Fonetica Sperimentale, Trento, pp. 99-116.

Delmonte R., Cristea D., Petrea M. and Bacalu, C. (1995) PROSODICS - a tool to improve pronunciation of a foreign language, Technical Report, Laboratorio di Linguistica Computazionale, Università di Venezia.

Delmonte, R., Cristea D., Petrea M., Bacalu, C. and Stiffoni F. (1996) Modelli Fonetici e Prosodici per SLIM, Atti $6^{\circ}$ Convegno GFS-AIA, Roma, pp. 47-58.

Delmonte, R., Cacco, A., Romeo, L., Dan, M., Mangilli-Climpson, M. and Stiffoni, F. (1996) SLIM - AModel for Automatic Tutoring of Language Skills, Ed-Media 96, AACE, Boston.

Delmonte, R. (1997) Learning Languages with a 'SLIM' Automatic Tutor. Asiatica Venetiana 2: $31-52$.

Delmonte, R., Petrea, M. and Bacalu, C. (1977) SLIM Prosodic Module for Learning Activities in a Foreign Language, Proceedings of ESCA, Eurospeech97, Rhodes, Vol.2, pp. 669-672.

Delmonte, R. (1998) Le nuove tecnologie e l'insegnamento della lingua straniera, Venezia: Periplo.

Delmonte, R. (1998) Prosodic modeling for automatic language tutors, Proceedings of STiLL 98, ESCA, Sweden, pp. 57-60.

Delmonte, R. (1998) L'apprendimento delle regole fonologiche inglesi per studenti italiani. Atti $8^{\circ}$ Convegno GFS-AIA, Pisa, pp. 177-191.

Delmonte, R. (1999) A prosodic module for self-learning activities, Proceedings of MATISSE, London, pp. 129-132.

Delmonte, R. (1999) La variabilità prosodica: dalla sillaba al contenuto informativo. Atti $9^{\circ}$ Convegno GFS-AIA, Venezia, pp. 133-146.

Delmonte, R. (2000) SLIM prosodic automatic tools for self-learning instruction, Speech Communication 30: 145-166.

Delmonte, R. (2000) Speech synthesis for language tutoring systems - some examples, Proceedings of InSTIL2000, Dundee, 25.

Dickinson, L. (1987) Self-Instruction in Language Learning. Cambridge: Cambridge University Press.

Halliday, M. A. K. (1970) Functions and universals of language. In: Kress, G. (ed.), System and Functions in Language. Oxford: Oxford University Press.

Henning, G. (1987) A Guide to Language Testing, Newbury House.

Hardisty, D. and Windeatt, S., (1989) CALL, Oxford: Oxford University Press.

Higgins, J. J. (1991) Grammarland: A non-directive use of the computer in language teaching. ELT Journal 39 (3): 167-173.

Higgins, J. J. (1988) Language, Learners \& Computers, London: Longman.

Hughes A. and Porter D. (eds.) (1983) Current Developments in Language Testing. London: Academic Press.

Jonassen, D. H. (1986) Hypertext principles for text and courseware design. Educational Psychologist 21 (6): 269-292.

Jonassen, D. H. and Mandl, H. (eds.) (1990) Designing Hypermedia for Learning. Berlin: Springer-Verlag.

Jun, H. (1987) Avideo \& computer-aided English course. ELT Journal 41 (1): 37-45.

Knowles, G. (1986) The role of the computer in the teaching of phonetics. In: Leech G. and 
Candlin, C. N. (eds.), Computers in English Language Teaching \& Research. London: Longman, pp. 133-148.

Leech, G. and Candlin, C. N. (eds.) (1986) Computers in English Language Teaching and Research. London: Longman.

Lyster, R. and Ranta, L. (1997) Corrective feedback and learner uptake. Studies in Second Language Acquisition, 19: 37-66.

Mangilli-Climpson, M. (1990) Silents for speaking. Perspectives: TESOL-Italy 16(1):43-51.

Nunan, D. (1988) Syllabus Design. Oxford: Oxford University Press.

Oller, J. W. (1979) Language Tests at School. London: Longman.

Page, B. (1996), Modern Languages: Learning, Teaching, Assessment. A Common European Framework of Reference. Guide for Teachers, Strasbourg, December 1996, CC-LANG (96) 13 rev.

Picher, O., Berk, E., Devlin, J. and Pugh, K. (1991) Hypermedia. In: Berk, E. and Devlin, J. (eds.), Hypertext/Hypermedia Handbook. NY: McGraw-Hill, pp. 23-54.

Rea-Dickens, P. and Germaine, K. (1992) Evaluation. Oxford: Oxford University Press.

Roe, P. and Richards, K. (eds.) (1995) Distance Learning in ELT. London.

Rowntree, D. (1986) Teaching Through Self-Instruction. London: Kogan Page.

Scardamalia, M., Bereiter, C., McLean, R., Swallow, J. and Woodruff, E. (1989) Computer-supported intentional learning environments. Journal of Educational Computing Research 5: $51-68$.

Scrimshaw, P. (ed.) (1993) Language, Classrooms \& Computers. London: Routledge.

Stempleski, S. and Tomalin, B. (1990) Video in Action. London: Prentice Hall International.

Terry, S. (1989) Learner trainer for self access CALL: a summary \& a suggestion. MUESLI NEWS (IATEFL Micro Users in English as a Second Language Institutions Special Interest Group), February 1989: 3-5.

Trim, J. and Brumfit, C. (eds.) The Council of Europe and Language Teaching London: Modern English Publications with The British Council, in corso di stampa 1994/95.

Ueyama, M. (1997) The phonology and phonetics of second language intonation: the case of 'Japanese English'. Proceedings of ESCA'97, 5:2411-2414.

Vesterinen, J., McKee, H. and Laine, P. (1994) Communicative interaction - from a distance. Language \& Intercultural Training 15 (2): 10-11.

Weir, C. J. (1990) Communicative Language Testing. London: Prentice Hall International.

Wenden, A. (1991) Learner Strategies for Learner Autonomy. London: Prentice Hall.

Whalley, P. (1993) An alternative rhetoric for Hypertext. In: McKnight, C., Dillon, A. and Richardson J. (eds.), Hypertext, a Psychological Perspective. NY: Ellis Horwood, 6-17.

Yalden, J. (1987) Principles of Course Design for Language Teaching :Cambridge University Press. 